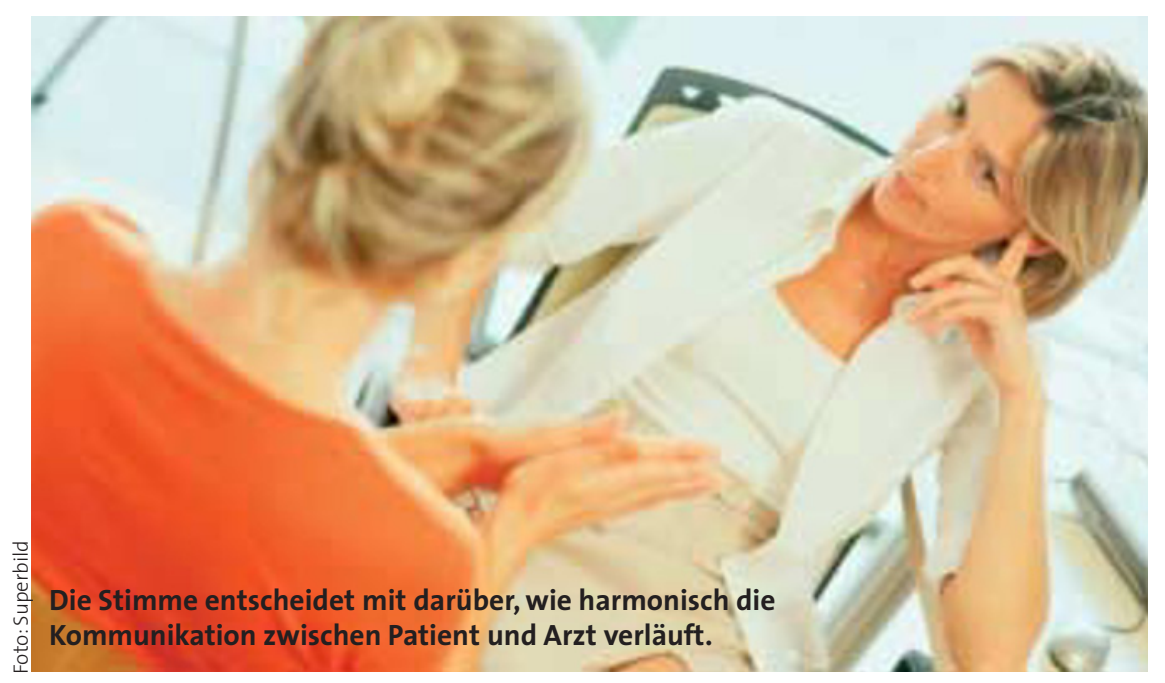

\title{
Patientengespräch
}

\section{Achten Sie mehr auf Ihre Stimme!}

\author{
Haben Sie schon einmal darüber nachgedacht, ob Sie laut oder leise sprechen? \\ Glauben Sie, das sei ein unveränderlicher, persönlicher Parameter, \\ ohne jede Bedeutung für Ihre Patienten? Wenn ja, dann sollten Sie sich \\ dringend mit der potenziellen Wirkung Ihrer Stimme beschäftigen.
}

— Eine leise Stimme kann beruhigend wirken, kann aber auch als Schwäche oder als Zeichen von Zurückhaltung oder gar Ablehnung interpretiert werden. Im Allgemeinen weist eine leise Stimme auf einen geringen Energieeinsatz hin.

Eine laute Stimme dagegen kann Kompetenz demonstrieren und Stärke ausdrücken, was aber auf manche Patienten erschreckend wirkt.

Ob Sie leise oder laut sprechen, sollten Sie im Umgang mit Patienten nicht dem Zufall überlassen. Beobachten Sie die Reaktion Ihres Patienten auf die Schwankungen Ihrer Stimme: Wird er „zutraulicher“, wenn Sie leiser sprechen? Reagiert er freundlicher, geht er besser mit, wenn Sie lauter sprechen? Beobachten Sie auch seine Körpersprache, etwa sein Abstand-Nähe-Verhalten. Variieren Sie einfach mal ein wenig. Fühlen Sie mit, wie sich Ihr Patient verhält.

Wie in jeder zwischenmenschlichen Beziehung erlebt man hier entweder - den Typ, der einen sich selbst ähnlichen Partner sucht oder
- den Typ, der Ergänzung und Korrektur benötigt.

Beispiele sind die erschöpfte alleinerziehende Mutter, die sich bei einer leisen, sanften Ärztin gut aufgehoben fühlt. Oder der Teenager, der mit einer gewissen Verehrung zu seinem starken, sportlichen „Doc" aufschaut.

Sollten Sie also bisher gewohnheitsmäßig laut oder immer leise sprechen, dann lohnt es sich, diesen Aspekt Ihres ärztlichen Verhaltens einmal bewusst zu variieren und die Reaktionen in der Interaktion zu beobachten. Das Gleiche gilt bei Patienten, deren Stimmführung in dieser Hinsicht auffällig erscheint.

Das hier beschriebene Vorgehen dient dem besseren Wohlbefinden und der persönlichen, menschlichen Stärkung von Arzt und Patient. Es handelt sich um Manipulation im positiven Sinne, eine Technik zum bewussten freundlich-empathischen Umgang miteinander - die allerdings nur funktioniert, wenn Sie es ehrlich meinen.

DR. ROMAN MACHENS = 